\title{
Korean Version of Mini Mental Status Examination for Dementia Screening and Its' Short Form
}

\author{
Tae Hui Kim ${ }^{1}$, Jin Hyeong Jhoo ${ }^{2}$ \\ Joon Hyuk Park ${ }^{3}$, Jeong Lan Kim ${ }^{4}$ \\ Seung Ho Ryu ${ }^{6}$, Seok Woo Moon ${ }^{7}$ \\ II Han $\mathrm{Choo}^{8}$, Dong Woo Lee \\ Jong Chul Yoon ${ }^{10}$, Yeon Ja Do' \\ Seok Bum Lee ${ }^{5}$, Moon Doo Kim ${ }^{3}$ \\ Ki Woong Kim ${ }^{1,11} \bowtie$ \\ ${ }^{1}$ Department of Neuropsychiatry, \\ Seoul National University \\ Bundang Hospital, Seongnam, \\ ${ }^{2}$ Department of Neuropsychiatry, \\ Kangwon National University Hospital, \\ Chuncheon, \\ ${ }^{3}$ Department of Neuropsychiatry, \\ Jeju National University Hospital, Jeju, \\ ${ }^{4}$ Department of Psychiatry, \\ Chungnam National University \\ Hospital, Daejeon, \\ ${ }^{5}$ Department of Psychiatry, \\ Dankook University Hospital, Cheonan, \\ ${ }^{6}$ Department of Neuropsychiatry, \\ Konkuk University Hospital, Seoul, \\ ${ }^{7}$ Department of Psychiatry, \\ Konkuk University Chungju Hospital, \\ Chungju, \\ ${ }^{8}$ Department of Neuropsychiatry, \\ Inje University Snaggye Paik Hospital, \\ Seoul, \\ ${ }^{9}$ Department of Neuropsychiatry, \\ Seoul National University Hospital, Seoul, \\ ${ }^{10}$ Departmnet of Neuropsychiatry, \\ Kyunggi Provincial Hospital \\ for the Elderly, Yongin, \\ ${ }^{11}$ Department of Psychiatry, \\ Seoul National University \\ College of Medicine, Seoul, Korea
}

\section{$\triangle$ Correspondence}

Ki Woong Kim, MD, PhD

Department of Neuropsychiatry, Seoul National University Bundang Hospital, 166 Gumi-ro, Bundang-gu, Seongnam 463-707, Korea

Tel +82-31-787-7439

Fax $+82-31-787-4058$

E-mail kwkimmd@snu.ac.kr

(c) This is an Open Access article distributed under the terms of the Creative Commons Attribution Non-Commercial License (http://creativecommons.org/licenses/by-nc/3.0) which permits unrestricted non-commercial use, distribution, and reproduction in any medium, provided the original work is properly cited.
Objective We developed a Korean version of Mini-Mental Status Examination (MMSE) optimized for screening dementia (MMSE-DS) and its' short form (SMMSE-DS).

Methods We constructed the MMSE-DS using the items of the two current Korean versions of MMSE and then construct the SMMSE-DS consisted of 13 items from the MMSEDS based on the diagnostic accuracy of individual items for dementia. We investigated reliability and validity of MMSE-DS and SMMSE-DS on 1,555 subjects (1,222 nondemented controls, 333 dementia patients). We compared the diagnostic accuracy of the SMMSE-DS with that of the three full Korean versions of MMSE, and examined its' age- and education-specific optimal cutoff scores for dementia.

Results The internal consistency obtained by Cronbach's coefficient alpha was 0.826 . The inter-rater reliability and test-retest reliability were $0.968(\mathrm{p}<0.001)$ and $0.825(\mathrm{p}<0.001)$, respectively. It showed significant correlation with the Clinical Dementia Rating (CDR) ( $\mathrm{r}=-0.698$, $\mathrm{p}<0.05)$ and the three full Korean versions of MMSE $(r=0.839-0.938, p<0.001)$. The area under the receiver operator curve for dementia of the SMMSE-DS was larger than those of the three full Korean versions of MMSE $(p<0.001)$. Age, education and gender explained $19.4 \%$ of the total variance of SMMSE-DS scores. The optimal cutoff scores for dementia of the SMMSE-DS were estimated differently by age and educational attainment of the subjects.

Conclusion The SMMSE-DS was found to be accurate, brief and portable instrument for screening dementia in Korean elders, and may be particularly useful for screening dementia in elderly populations with wide variation in educational levels.

Psychiatry Investig 2010;7:102-108

Key Words Mini-Mental Status Examination, Short form, Dementia, Validity, Reliability, Korean.

Received: February 2, 2010 Accepted: February 26, 2010 Available online: April 6, 2010

\section{Introduction}

The prevalence of dementia is increasing and interventions are more widely available. This creates a need for accurate screening tests for early detection of the condition. Ideally, such tests should be adequately sensitive and specific to identify cognitively impaired individuals requiring comprehensive evaluation and management, and could be quickly and easily administered not only by physicians but also by nurses or other trained healthcare personnel.

The Mini-Mental Status Examination (MMSE) is the most widely used screening instrument for dementia. ${ }^{1-4}$ The MMSE contains 19 items and the maximum score is 30 points (10 points for orientation, 6 for verbal memory, 5 for concentration and calculation, 5 for language, 3 for praxis, 1 for visuospatial construction). Three Korean versions ${ }^{5-7}$ have been standardized and normative data have been obtained in tests with elderly Korean indivduals. ${ }^{8,9}$

However, MMSE, in the current form, has several limitations in dementia screening despite excellent inter-rater reliability and good criterion and construct validity. ${ }^{10-13}$ First, MMSE is not fully optimized for screening dementia because the test was originally developed to evaluate elderly psychiatric patients rather than those with dementia. ${ }^{14,15}$ For example, the relative 
weight of items for memory, which is the earliest and most common cognitive deficit in dementia, is only 6 of 30 points. This low weight is associated with a reduced diagnostic accuracy of MMSE in dementia assessment compared with other screening tests such as the Revised Hasegawa Dementia Scale (HDS-R). ${ }^{16,17}$ Second, MMSE performance in dementia diagnosis is more significantly influenced by educational level than are other screening instruments. ${ }^{18-21}$ Finally, MMSE cannot be fully administered to disabled elderly individuals with motor impairment because MMSE contains performance tests that assess praxis and visuospatial function.

Therefore, we developed a short version of the MMSE for dementia screening (SMMSE-DS) which is more accurate, briefer and can be administered more easily to the individuals with motor impairment on the basis of the diagnostic accuracy of each MMSE item for dementia, and then examined the psychometric properties of the SMMSE-DS system.

\section{Methods}

\section{Subjects}

All subjects were Korean elders aged 60 years or over. Cognitively normal control subjects were recruited from participants in the Korean Longitudinal Study on Health and Aging (KLoSHA $)^{22}$ or from volunteers in the National Dementia Screening and Registry Program (NDSRP). The KLoSHA is a population-based longitudinal study on health, aging and common geriatric diseases in Korean elderly aged 65 years and older. The subjects with dementia were recruited either from the participants of the KLoSHA or the visitors to the Dementia Clinics of eight university hospitals in 2009.

\section{Assessment}

Each subject was examined by a geropsychiatrist with advanced training in the neuropsychiatry and dementia research according to the protocol of the Korean version of the Consortium to Establish a Registry for Alzheimer's disease (AD) Assessment Packet (CERAD-K). ${ }^{6}$ Three Korean versions of MMSE were coadministered to evaluate the concurrent validity of SMMSE-DS. Two of these questionnaires \{Korean version of MMSE in the CERAD-K (MMSE-KC) ${ }^{6}$ and Korean version of MMSE in the Seoul Neuropsychological Screening Battery $(\mathrm{K}-\mathrm{MMSE})^{23}$ \} had been previously standardized, but one version (MMSE-DS) was newly constructed, within the present study, to develop the SMMSE-DS. Subjects diagnosed with dementia by the criteria of the Diagnostic and Statistical Manual of Mental Disorders, 4th edition (DSM-IV), ${ }^{24}$ were enrolled in the patient group. Those who were functioning independently in the community and did not show any cognitive impairment formed the control group. Subjects with serious medical, psychiatric, or neurological disorders that might have affected cognitive function were excluded.

\section{Formulation of the SMMSE-DS}

We initially prepared a new Korean version of the MMSEDS. All items of MMSE-DS, with the exception of a single question, were adapted from either MMSE-KC ${ }^{6}$ or K-MMSE. ${ }^{7}$ The five items for time orientation were adapted from MMSE-KC without modification. Five questions exploring for place orientation were adapted from the MMSE-KC with minor modification of scoring criteria. Three words testing immediate and delayed recall were adapted from MMSE-KC (tree, car, and cap), as these terms are more frequently used by Koreans ${ }^{25}$ than those in the K-MMSE. Serial 7s in the K-MMSE was adapted for the item testing concentration in the MMSE-DS. The items for naming test were also adapted from the K-MMSE (watch, pencil) since the items of the K-MMSE were easier to carry than those of the MMSE-KC (stamp, key). The repetition unit was adapted from MMSE-KC, as this may be less influenced by educational level than is the equivalent items in K-MMSE. The items for ideational praxis were adapted from the MMSE-KC since they were more similar to those in the original English version of MMSE than those of the K-MMSE. The visuospatial construction item was taken from the original English version of MMSE. Terms assessing reading and writing in the original English version of MMSE were modified into items evaluating judgment and abstract thinking, because $40.1 \%$ of Korean elders aged 65 years or more have not received formal education. ${ }^{26}$ The item for testing judgment was adapted from the MMSE-KC ("Why do you wash your clothes?"). Interpretation of a familiar Korean proverb ("Many a little makes a mickle.") was used to test abstract thinking.

Next, we examined changes in areas under receiver operator curves (AUCs) of MMSE-DS excluding individual items, and constructed the 20-point SMMSE-DS by discarding the items that was not found to contribute to the diagnostic accuracy of the MMSE-DS for dementia.

\section{Data analysis}

To evaluate inter-rater reliability, two raters simultaneously assessed 31 participants (11 control subjects; 20 dementia patients). To examine test-retest reliability, the same raters administered MMSE-DS to the same participants 4 weeks after initial assessment. Inter-rater and test-retest reliability was determined using Pearson correlation coefficients, and internal consistency was examined using Cronbach's alpha coefficient.

To evaluate discriminant validity, mean scores of the MMSE-DS and SMMSE-DS of patient and control groups were compared by analysis of variance (ANOVA). The univariate normality assumptions were verified using the Welch and Brown-Forsythe modifications of Levene's test. The GamesHowell multiple comparison technique was applied post-hoc to ANOVA data.

To evaluate concurrent validity, correlations of MMSE-DS and SMMSE-DS with the other two Korean versions of MM- 
SE (MMSE-KC and K-MMSE) were examined using twotailed Pearson correlation tests, and correlations with the Clinical Dementia Rating (CDR ${ }^{27}$ were examined by the Spearman rank-order correlation test.

We derived optimal cut-off scores satisfying both sensitivity and specificity criteria for dementia using receiver-operator characteristic (ROC) analysis. To assess the diagnostic accuracy of each test for dementia, we compared the AUCs of
MMSE-DS, SMMSE-DS, MMSE-KC and K-MMSE by calculating the critical ratio " $z$ ", as proposed by Hanley and McNeil. ${ }^{28}$ Multiple linear regression analysis with stepwise variable selection assessed the relative contributions of age, education, and gender to MMSE-DS and SMMSE-DS scores. All statistical analyses were performed using Statistical Package for the Social Sciences (SPSS)(version 17.0) for Windows (SPSS Inc., Chicago, IL, USA).

Table 1. Demographic and clinical characteristics of the subjects

\begin{tabular}{|c|c|c|c|c|c|c|c|}
\hline & \multirow{2}{*}{ Controls } & \multicolumn{4}{|c|}{ Dementia } & \multicolumn{2}{|c|}{ Statistics } \\
\hline & & $\mathrm{CDR}=0.5$ & $\mathrm{CDR}=1$ & $\mathrm{CDR}=2$ & $\mathrm{CDR}=3$ & $\mathrm{~F}^{\dagger}$ or $\chi^{2}$ & Posthoc $\ddagger$ \\
\hline Number & 1,222 & 143 & 127 & 49 & 14 & & \\
\hline Age (years) & $72.29 \pm 6.24^{\mathrm{a}}$ & $75.59 \pm 7.66^{\mathrm{b}}$ & $77.65 \pm 7.92^{\mathrm{b}}$ & $77.69 \pm 8.97^{\mathrm{b}}$ & $78.71 \pm 12.18^{\mathrm{b}}$ & $32.07^{* *}$ & $\mathrm{a}<\mathrm{b}$ \\
\hline Gender (female, \%) & 63.6 & 62.2 & 66.9 & 83.7 & 71.4 & 9.25 & \\
\hline Education (years) & $6.92 \pm 5.22^{\mathrm{a}}$ & $7.31 \pm 5.84^{\mathrm{a}}$ & $6.13 \pm 5.62^{\mathrm{a}}$ & $4.90 \pm 5.49^{\mathrm{b}}$ & $3.29 \pm 4.73^{\mathrm{b}}$ & $4.09^{*}$ & $\mathrm{a}<\mathrm{b}$ \\
\hline MMSE-DS & $24.85 \pm 3.84^{\mathrm{a}}$ & $18.70 \pm 5.51^{\mathrm{b}}$ & $14.79 \pm 5.28^{\mathrm{c}}$ & $11.43 \pm 4.43^{\mathrm{d}}$ & $6.29 \pm 4.48^{\mathrm{e}}$ & $371.77^{* *}$ & $\mathrm{a}>\mathrm{b}>\mathrm{c}>\mathrm{d}>\mathrm{e}$ \\
\hline SMMSE-DS & $17.19 \pm 2.16^{\mathrm{a}}$ & $12.74 \pm 3.31^{\mathrm{b}}$ & $9.98 \pm 3.16^{\mathrm{c}}$ & $7.86 \pm 2.84^{\mathrm{d}}$ & $5.14 \pm 3.01^{\mathrm{e}}$ & $545.06^{* *}$ & $\mathrm{a}>\mathrm{b}>\mathrm{c}>\mathrm{d}>\mathrm{e}$ \\
\hline MMSE-KC & $24.29 \pm 4.06^{\mathrm{a}}$ & $18.31 \pm 5.36^{\mathrm{b}}$ & $14.68 \pm 5.04^{\mathrm{c}}$ & $11.06 \pm 4.07^{\mathrm{d}}$ & $5.79 \pm 3.33^{\mathrm{e}}$ & $334.26^{* *}$ & $\mathrm{a}>\mathrm{b}>\mathrm{c}>\mathrm{d}>\mathrm{e}$ \\
\hline K-MMSE & $24.75 \pm 4.18^{\mathrm{a}}$ & $19.49 \pm 5.67^{b}$ & $15.60 \pm 5.96^{\mathrm{c}}$ & $12.20 \pm 4.77^{\mathrm{d}}$ & $6.93 \pm 4.48^{\mathrm{e}}$ & $265.99^{* *}$ & $\mathrm{a}>\mathrm{b}>\mathrm{c}>\mathrm{d}>\mathrm{e}$ \\
\hline
\end{tabular}

${ }^{*} \mathrm{p}<0.05,{ }^{* *} \mathrm{p}<0.001,{ }^{\dagger}$ Welch one-way ANOVA, ${ }^{\ddagger}$ Games-Howell posthoc comparisons. CDR: Clinical Dementia Rating, MMSE-DS: Mini Mental Status Examination for dementia screen, SMMSE-DS: short version of MMSE-DS, MMSE-KC: Korean version of MMSE in the CERAD-K, K-MMSE: Korean version of MMSE in the Seoul Neuropsychological Screening Battery, ANOVA: analysis of variance, CERAD-K: Korean version of the Consortium to Establish a Registry for Alzheimer's disease Assessment Packet

Table 2. Changes in AUC of the MMSE-DS by excluding items

\begin{tabular}{|c|c|c|c|c|}
\hline Excluded item & $\operatorname{AUC}(95 \% \mathrm{CI})$ & Difference & $\mathrm{SE}$ & Z \\
\hline None & $0.895(0.880-0.911)$ & Reference & & \\
\hline Time orientation $\left(\right.$ year) ${ }^{\dagger}$ & $0.894(0.879-0.910)$ & -0.001 & 0.000676 & 1.69 \\
\hline Time orientation (season) ${ }^{\dagger}$ & $0.893(0.877-0.909)$ & -0.005 & 0.000562 & $4.44^{* *}$ \\
\hline Time orientation (date) ${ }^{\dagger}$ & $0.889(0.873-0.905)$ & -0.006 & 0.000869 & $7.37^{* *}$ \\
\hline Time orientation (day) ${ }^{\dagger}$ & $0.890(0.874-0.906)$ & -0.005 & 0.000788 & $6.41^{* *}$ \\
\hline Time orientation (month) ${ }^{\dagger}$ & $0.892(0.877-0.908)$ & -0.003 & 0.000635 & $4.53^{* *}$ \\
\hline Place orientation (state) & $0.896(0.880-0.911)$ & 0.006 & 0.000559 & 1.07 \\
\hline Place orientation (county) ${ }^{\dagger}$ & $0.887(0.871-0.903)$ & -0.008 & 0.000809 & $10.24^{*}$ \\
\hline Place orientation (town) ${ }^{\dagger}$ & $0.890(0.874-0.906)$ & -0.005 & 0.000992 & $5.01^{* *}$ \\
\hline Place orientation (floor) ${ }^{\dagger}$ & $0.889(0.873-0.905)$ & -0.006 & 0.000768 & $8.20^{* *}$ \\
\hline Place orientation (place) $)^{\dagger}$ & $0.894(0.878-0.909)$ & -0.002 & 0.000660 & $2.76^{*}$ \\
\hline Registration (three words) ${ }^{\dagger}$ & $0.896(0.881-0.912)$ & 0.001 & 0.000884 & 1.26 \\
\hline Attention and calculation (Serial 7s) & $0.915(0.902-0.929)$ & 0.020 & 0.00327 & $6.13^{* *}$ \\
\hline Recall (three words) ${ }^{\dagger}$ & $0.883(0.866-0.899)$ & -0.013 & 0.00259 & $4.89^{* *}$ \\
\hline Naming ${ }^{\dagger}$ & $0.895(0.879-0.911)$ & 0.000 & 0.000455 & 0.69 \\
\hline Repetition & $0.899(0.883-0.914)$ & 0.003 & 0.000754 & $4.35^{* *}$ \\
\hline Three-stage command ${ }^{\dagger}$ & $0.893(0.877-0.908)$ & -0.002 & 0.00147 & 1.87 \\
\hline Copying interlocking pentagons & $0.902(0.887-0.917)$ & 0.006 & 0.00100 & $6.20^{* *}$ \\
\hline Judgment & $0.895(0.879-0.911)$ & 0.000 & 0.000168 & $2.02 *$ \\
\hline Abstract thinking & $0.896(0.881-0.912)$ & 0.001 & 0.000577 & 1.44 \\
\hline
\end{tabular}

${ }^{*} \mathrm{p}<0.05,{ }^{*} \mathrm{p}<0.001$, by Hanley \& McNeil, ${ }^{28}$ titems selected in the short version of MMSE-DS (SMMSE-DS). AUC: areas under receiver operator curves, MMSE-DS: Mini Mental Status Examination for dementia screen, CI: confidence interval, SE: standard error 


\section{Results}

\section{Subjects}

A total of 1,555 subjects (1,222 nondemented controls; 333 dementia patients) were included in the present study. Among dementia patients, 142 had very mild dementia $(\mathrm{CDR}=0.5), 127$ mild $(\mathrm{CDR}=1), 50$ moderate $(\mathrm{CDR}=2)$, and 14 severe $(\mathrm{CDR}=$ $3)$. A total of 242 patients $(72.7 \%)$ were diagnosed with $A D$, $46(13.8 \%)$ with vascular dementia (VD), 46 (13.8\%) with dementia with Lewy body (DLB), 14 (4.2\%) with frontotemporal dementia (FTD), and $8(2.4 \%)$ with dementia of other etiologies. Demographic and clinical characteristics of all patients are summarized in Table 1.

\section{Construction of SMMSE-DS}

As shown in Table 2, the AUC of MMSE-DS increased when the six items testing place orientation for state, registration, attention/calculation, repetition, visuospatial construction and judgment were excluded, and the differences reached a statistical significance in the items for attention/calculation $(\mathrm{z}=6.13, \mathrm{p}<0.001)$, repetition $(\mathrm{z}=4.35, \mathrm{p}<0.001)$ and visuospatial construction $(z=6.20, p<0.001)$. Of these items, five (orientation for state, attention/calculation, repetition, visuospatial construction and judgment) were not included in the SMMSE-DS. The item for registration was not discarded because this is a prerequisite for testing recall. In addition, we discarded the item testing abstract thinking because this was not included in the original English version of the MMSE, and the contribution of this item to the diagnostic accuracy of MMSEDS was not statistically significant $(\mathrm{z}=1.44, \mathrm{p}>0.05)$. Thus, SMMSE-DS is a 20-point scale containing 13 items including time orientation ( 5 points), place orientation ( 4 points), verbal memory ( 6 points), naming ( 2 points), and praxis ( 3 points).

\section{Reliability}

Both the MMSE-DS and SMMSE-DS showed excellent internal consistency. The Cronbach's alpha coefficients of the scales were 0.826 and 0.806 , respectively. Inter-rater and test-retest reliabilities were $0.999(\mathrm{p}<0.001$, Pearson correlation test) and $0.935(\mathrm{p}<0.001$, Pearson correlation test), re- spectively, for MMSE-DS, and 0.968 ( $\mathrm{p}<0.001$, Pearson correlation test) and $0.826(\mathrm{p}<0.001$, Pearson correlation test), respectively, for SMMSE-DS.

\section{Validity}

As shown in Table 1, SMMSE-DS, MMSE-DS, MMSE$\mathrm{KC}$, and K-MMSE scores differed significantly between control and dementia patients. As CDR increased in dementia patients, scores decreased significantly ( $\mathrm{p}<0.001$ by ANOVA). On posthoc analysis, scores were significantly lower in patients with dementia compared with control individuals, indicating that all of SMMSE-DS, MMSE-DS, MMSE-KC, and KMMSE could validly discriminate between control and dementia patients. SMMSE-DS scores were significantly correlated with scores of the MMSE-DS ( $\mathrm{r}=0.938, \mathrm{p}<0.001)$, MMSE-K $(\mathrm{r}=0.924, \mathrm{p}<0.001), \mathrm{K}-\mathrm{MMSE}(\mathrm{r}=0.839, \mathrm{p}<0.001)$, and CDR

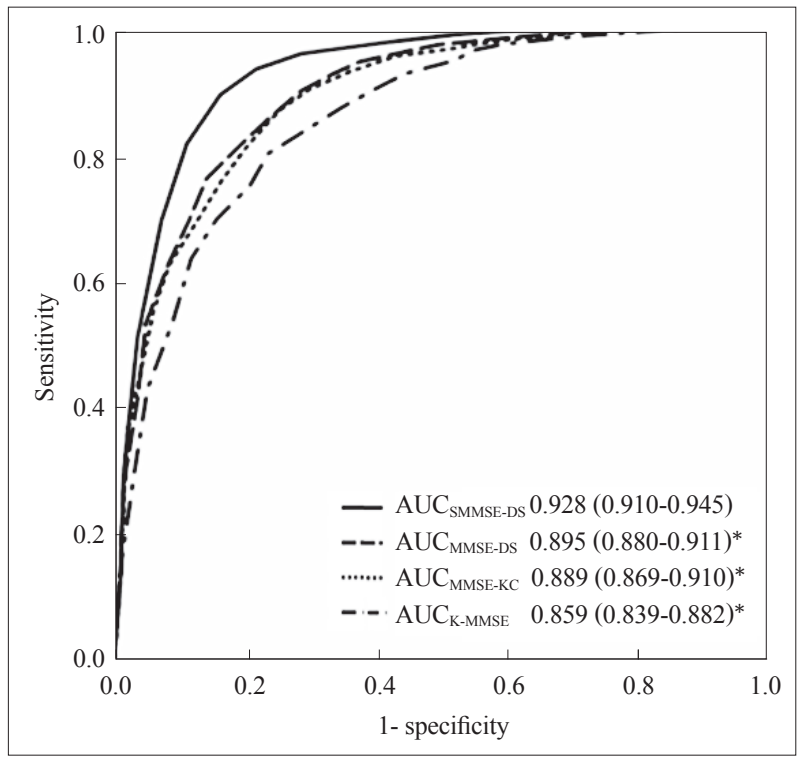

Figure 1. Comparison of areas under the receiver operator curve (AUC) of the short version of Mini-Mental Status Examination for dementia screen (SMMSE-DS) with those of the three full Korean versions of MMSE. ${ }^{*} p<0.001$. MMSE-KC: Korean version of MMSE in CERAD-K ${ }^{6}$, K-MMSE: Korean version of MMSE in the Seoul Neuropsychological Screening Battey, ${ }^{7}$ CERAD-K: Korean version of the Consortium to Establish a Registry for Alzheimer's disease Assessment Packet.

Table 3. Concurrent validity of the SMMSE-DS

\begin{tabular}{lccccc}
\hline & SMMSE-DS & MMSE-DS & MMSE-KC & K-MMSE & CDR \\
\hline SMMSE-DS & 1 & $0.938^{* *}$ & $0.924^{* *}$ & $0.839^{* *}$ & $-0.654^{*}$ \\
MMSE-DS & - & 1 & $0.955^{* *}$ & $0.946^{* *}$ & $-0.654^{*}$ \\
MMSE-KC & - & - & 1 & $0.908^{* *}$ & $-0.652^{*}$ \\
K-MMSE & - & - & - & 1 & $-0.592^{*}$ \\
CDR & - & - & - & - & 1 \\
\hline
\end{tabular}

${ }^{*} \mathrm{p}<0.001$, spearman rank test, ${ }^{* *} \mathrm{p}<0.001$, pearson correlation test. MMSE-DS: Mini Mental Status Examination for dementia screen, SMMSE-DS: short version of MMSE, MMSE-KC: Korean version of MMSE in the CERAD-K ${ }^{6}$, K-MMSE: Korean version of $\mathrm{MMSE}^{7}$ in the Seoul Neuropsychological Screening Battery, ${ }^{23}$ CDR: Clinical Dementia Rating, ${ }^{31}$ CERAD-K: Korean version of the Consortium to Establish a Registry for Alzheimer's disease Assessment Packet 
$(\mathrm{r}=-0.698, \mathrm{p}<0.05)$, indicating that SMMSE-DS had a high concurrent validity (Table 3 ).

\section{Diagnostic accuracy and optimal cutoff scores}

The AUCs of the SMMSE-DS (AUC $\mathrm{AMMSE}_{\mathrm{S}}$ ), MMSE-DS (AUC $\left.\mathrm{AMSE}_{\mathrm{MMS}}\right)$, MMSE-KC (AUC $\left.\mathrm{AMSE}_{\text {MC }}\right)$, and $\mathrm{K}-\mathrm{MMSE}$ $\left(\mathrm{AUC}_{\mathrm{K}-\mathrm{MMSE}}\right)$ were all greater than 0.80 , indicating that all tests were useful in detecting dementia. AUC $\mathrm{C}_{\text {SMMSE-DS }}$ was significantly greater than $\mathrm{AUC}_{\text {MMSE-DS }}(\mathrm{z}=6.98, \mathrm{p}<0.001), \mathrm{AUC}_{\text {MMSE-KC }}$ $(\mathrm{z}=7.56, \mathrm{p}<0.001)$, and $\mathrm{AUC}_{\mathrm{K}-\mathrm{MMSE}}(\mathrm{z}=9.20, \mathrm{p}<0.001)$, indicating that SMMSE-DS may be more accurate for the diagnosis of dementia than are the other three full Korean versions of MMSE (Figure 1).

In subjects educated for 6 years or less, the AUCs of SM-
MSE-DS, MMSE-DS, MMSE-KC, and K-MMSE were 0.950 (0.937-0.963), 0.926 (0.909-0.942), 0.922 (0.905-0.939), and 0.892 (0.871-0.912), respectively. The $\mathrm{AUC}_{\text {SMMSE-DS }}$ was significantly larger than $\mathrm{AUC}_{\text {MMSE-DS }}(\mathrm{z}=4.619, \mathrm{p}<0.001)$, $\operatorname{AUC}_{\text {MMSE-KC }}(\mathrm{z}=5.047, \mathrm{p}<0.001)$, and $\mathrm{AUC}_{\mathrm{K}-\mathrm{MMSE}}(\mathrm{z}=6.819, \mathrm{p}<$ $0.001)$. In patients who had been educated for 7 years or more, the AUC values of SMMSE-DS, MMSE-DS, MMSE-KC, and K-MMSE were 0.921 (0.901-0.942), 0.917 (0.896-0.938), 0.916 (0.895-0.938), and 0.888 (0.862-0.914). The $\mathrm{AUC}_{\text {SMMSE-DS }}$ was larger than $\mathrm{AUC}_{\mathrm{K}-\mathrm{MMSE}}(\mathrm{z}=2.841, \mathrm{p}<0.01)$, but comparable to $\mathrm{AUC}_{\text {MMSE-DS }}(\mathrm{z}=0.728, \mathrm{p}=0.467)$ and $\mathrm{AUC}_{\text {MMSE-KC }}(\mathrm{z}=0.774$, $\mathrm{p}=0.439$ ).

Stepwise multiple regression analysis revealed that age, gender, and educational level significantly affected SMMSE-

Table 4. ROC analyses of the SMMSE-DS

\begin{tabular}{|c|c|c|c|c|}
\hline & Cutoffs* & Sensitivity & Specificity & $\mathrm{AUC}^{\dagger}$ \\
\hline \multicolumn{5}{|l|}{ Age $\leq 74$ years } \\
\hline \multirow[t]{3}{*}{ Education $\leq 6$ years $(\mathrm{N}=487)$} & $12 / 13$ & 0.964 & 0.821 & $0.950(0.912-0.988)$ \\
\hline & $13 / 14^{*}$ & 0.945 & 0.896 & \\
\hline & $15 / 16$ & 0.898 & 0.910 & \\
\hline \multirow[t]{3}{*}{ Education $\geq 7$ years $(\mathrm{N}=466)$} & $15 / 16$ & 0.953 & 0.712 & $0.908(0.857-0.958)$ \\
\hline & $16 / 17^{*}$ & 0.870 & 0.797 & \\
\hline & $17 / 18$ & 0.708 & 0.898 & \\
\hline \multirow[t]{3}{*}{ Overall $(\mathrm{N}=953)$} & $14 / 15$ & 0.938 & 0.786 & $0.919(0.885-0.952)$ \\
\hline & $15 / 16^{*}$ & 0.877 & 0.833 & \\
\hline & $16 / 17$ & 0.768 & 0.889 & \\
\hline \multicolumn{5}{|l|}{ Age $\geq 75$ years } \\
\hline \multirow[t]{3}{*}{ Education $\leq 6$ years $(\mathrm{N}=420)$} & $12 / 13$ & 0.875 & 0.830 & $0.934(0.910-0.958)$ \\
\hline & $13 / 14^{*}$ & 0.814 & 0.915 & \\
\hline & $14 / 15$ & 0.738 & 0.950 & \\
\hline \multirow[t]{3}{*}{ Education $\geq 7$ years $(\mathrm{N}=182)$} & $14 / 15$ & 0.957 & 0.697 & $0.917(0.874-0.961)$ \\
\hline & $15 / 16^{*}$ & 0.897 & 0.803 & \\
\hline & $16 / 17$ & 0.733 & 0.879 & \\
\hline \multirow[t]{3}{*}{ Overall $(\mathrm{N}=602)$} & $12 / 13$ & 0.911 & 0.744 & $0.912(0.888-0.937)$ \\
\hline & $13 / 14^{*}$ & 0.861 & 0.816 & \\
\hline & $14 / 15$ & 0.803 & 0.870 & \\
\hline \multicolumn{5}{|l|}{ All ages } \\
\hline \multirow[t]{3}{*}{ Education $\leq 6$ years $(\mathrm{N}=907)$} & $12 / 13$ & 0.928 & 0.827 & $0.950(0.932-0.967)$ \\
\hline & $13 / 14^{*}$ & 0.893 & 0.909 & \\
\hline & $14 / 15$ & 0.834 & 0.938 & \\
\hline \multirow[t]{3}{*}{ Education $\geq 7$ years $(\mathrm{N}=648)$} & $15 / 16$ & 0.941 & 0.760 & $0.921(0.891-0.952)$ \\
\hline & $16 / 17^{*}$ & 0.839 & 0.840 & \\
\hline & $17 / 18$ & 0.667 & 0.928 & \\
\hline \multirow[t]{3}{*}{ Overall $(\mathrm{N}=1,222)$} & $13 / 14$ & 0.935 & 0.784 & $0.928(0.910-0.945)$ \\
\hline & $14 / 15^{*}$ & 0.894 & 0.838 & \\
\hline & $15 / 16$ & 0.818 & 0.889 & \\
\hline
\end{tabular}

*optimal cut-off scores for dementia by ROC analyses, ${ }^{\dagger}$ area under the ROC with $95 \%$ confidence intervals. ROC: receiver operator curve, SMMSE-DS: short version of Mini Mental Status Exam for dementia screen, AUC: areas under receiver operator curve 
Table 5. Stepwise multiple linear regression of age, education and gender on the MMSE-DS and the SMMSE-DS

\begin{tabular}{|c|c|c|c|c|c|c|c|c|}
\hline & \multicolumn{4}{|c|}{ MMSE-DS } & \multicolumn{4}{|c|}{ SMMSE-DS } \\
\hline & B & SE (B) & $\beta$ & $\Delta \mathrm{R}^{2}$ & B & SE (B) & $\beta$ & $\Delta \mathrm{R}^{2}$ \\
\hline Age & -0.252 & 0.019 & $-0.301^{*}$ & 7.6 & -0.175 & 0.013 & $-0.325^{*}$ & $14.1^{\dagger}$ \\
\hline Education & 0.363 & 0.026 & $0.333^{*}$ & 21.0 & 0.127 & 0.018 & $0.181^{*}$ & $4.5^{\dagger}$ \\
\hline Gender & -2.87 & 0.30 & $-0.24^{*}$ & 1.0 & -0.761 & 0.194 & $-0.098^{*}$ & 0.8 \\
\hline
\end{tabular}

${ }^{*} \mathrm{p}<0.001$, stepwise multiple regression analyses, ${ }^{\dagger} \mathrm{p}<0.0001$, by $\mathrm{t}$ statistics comparing $\mathrm{R}$ of SMMSE-DS and MMSE-DS. B: regression coefficient, SE (B): standard error of $\mathrm{B}, \beta$ : standardized regression coefficient, $\Delta \mathrm{R}^{2}$ : percent variance explained by each variable, MMSEDS: Mini Mental Status Examination for dementia screen, SMMSE-DS: short version of MMSE-DS

DS and MMSE-DS scores (Table 5). These three demographic factors accounted for $19.4 \%$ and $29.6 \%$ of the total variance of SMMSE-DS and MMSE-DS, respectively. Although the demographic effect was significant in both tests, the overall $\mathrm{R}^{2}$ of demographic factors in the regression model of SMMSEDS was significantly smaller than that of the MMSE ( $\mathrm{t}=$ 13.98, d.f. $=1,554, \mathrm{p}<0.001$ ). Most of the difference in overall $\mathrm{R}^{2}$ between the two tests was attributable to the difference in the influence of education. The partial $\mathrm{R}^{2}$ of the educational level in the SMMSE-DS $(4.5 \%)$ was about one-fifth that in MMSE-DS $(21.0 \%)(\mathrm{t}=42.29, \mathrm{p}<0.001)$. The partial $\mathrm{R}^{2}$ age in SMMSE-DS was higher than that in MMSE-DS $(\mathrm{t}=12.19, \mathrm{p}<$ 0.001 ), and the partial $\mathrm{R}^{2}$ of gender in SMMSE-DS was similar to that in MMSE $(\mathrm{t}=1.17, \mathrm{p}>0.05)$.

The optimal cutoff scores for dementia of the SMMSE-DS stratified by age and educational level are shown in Table 4.

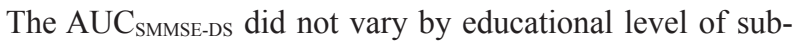
jects $(\mathrm{z}=1.58, \mathrm{p}>0.05)$.

\section{Discussion}

We developed the Korean version of MMSE optimized for screening dementia (MMSE-DS) and its' short version (SMMSE-DS).

Our results show that SMMSE-DS performed better than did full versions of the MMSE, displaying both higher AUC values and increased sensitivity and specificity for dementia regardless of educational level of the subjects. The superiority of SMMSE-DS over full versions of MMSE can be attributed principally to differences in the cognitive measures included in the tests. Compared with full versions of MMSE, the relative weights of measures for memory and orientation were strengthened in SMMSE-DS. Because these parameters examine cognitive domains impaired early in dementia, ${ }^{29,30}$ such variations may have improved the diagnostic accuracy of SMMSE-DS. In addition, SMMSE-DS can be used in the uneducated elderly population more readily than the full MMSE version, because the SMMSE-DS does not feature tests on reading, writing, or copying of interlocking pentagons. Because the MMSE showed a higher false-positive rate in educationally disadvantaged populations, ${ }^{17}$ differences in diagnostic accuracy between SMMSE-DS and the full MMSE versions may be greater in poorly educated subjects. As might be expected, the diagnostic accuracy for dementia of SMMSE-DS was better than that of complete versions of MMSE in lesseducated subjects, but was comparable to that of the full version MMSE in highly educated patients. These results indicate that the superiority of SMMSE-DS in the diagnosis of dementia, compared with complete versions of MMSE, may be greater in educationally disadvantaged populations.

The SMMSE-DS has several additional advantages in comparison with the full version of MMSE. First, SMMSE-DS is briefer than the full version of MMSE. Administration of SMMSE-DS takes much less time than is required for administration of full version MMSE because SMMSE-DS has less items than the full version MMSE (13 items versus 19 items). Second, SMMSE-DS is more portable than the full version of MMSE because SMMSE-DS does not include the paperand-pencil tests included in the full version MMSE, such as the copying of interlocking pentagons. The brevity and portability of SMMSE-DS may be advantageous over the full MMSE in mass screening of dementia.

The present study had some strengths. First, the proportion of very mild $(\mathrm{CDR}=0.5)$ and mild $(\mathrm{CDR}=1)$ dementia patients in our patient group exceeded $80 \%$ (very mild: $42.6 \%$, mild: $38.1 \%$ ), and our results can thus be extrapolated to detection of mild dementia. Many previous studies included participants with severe dementia, and few reports have provided information on the accuracy of screening tests in the detection of mild dementia. The diagnostic accuracy data of such studies may be most appropriately extrapolated to detection of moderate dementia. However, it would be better to enroll subjects with mild dementia, who are usually the focus of screening tests in evaluating screening tests. Second, we compared diagnostic accuracy not only using sensitivity and specificity values, but also using AUC data. Although assessment of diagnostic accuracy using sensitivity and specificity is common, this approach is adequate only when decision criteria such as a cutoff score are agreed among physicians, and are invariant. Moreover, the decision criterion is susceptible to differences in the characteristics of study sample. For example, the sensitivity and specificity of MMSE varied from $71-92 \%$, and $51-96 \%$, respectively. ${ }^{14,15}$ In contrast, an AUC value is independent of any decision criterion and is less influenced by 
extraneous factors that affect patient response, although an AUC cut-off is neither perfectly reliable nor completely valid because no such estimation is free from the influence of study design or administration procedure. Thus, AUC values provide a better measure of predictive accuracy than do sensitivity and specificity figures.

Two limitations are apparent in the present study. First, the concurrent validity of the SMMSE-DS was tested in comparison with three full Korean versions of MMSE which have many items in common with SMMSE-DS. This might have exaggerated the observed correlation coefficients. Second, the sources of control and patient groups were different. Most control subjects were community-dwelling elderly individuals, whereas the majority of dementia patients were recruited from subjects visiting hospitals. Such differences in sample source may have exaggerated the AUC values for dementia of the SMMSE.

In conclusion, SMMSE-DS is an accurate, brief, and portable instrument for screening dementia in Korean elderly individuals, and may be particularly useful in detecting dementia in elderly populations with wide variations in education level.

\section{-Acknowledgments}

This study was supported by a research grant from the Ministry of Health and Welfare, Korea (Grant NO. 08-2009-014).

\section{REFERENCES}

1. Folstein MF, Folstein SE, McHugh PR. "Mini-mental state". A practical method for grading the cognitive state of patients for the clinician. J Psychiatr Res 1975;12:189-198.

2. Malloy PF, Cummings JL, Coffey CE, Duffy J, Fink M, Lauterbach $\mathrm{EC}$, et al. Cognitive screening instruments in neuropsychiatry: a report of the Committee on Research of the American Neuropsychiatric Association. J Neuropsychiatry Clin Neurosci 1997;9:189-197.

3. Tombaugh TN, McIntyre NJ. The mini-mental state examination: a comprehensive review. J Am Geriatr Soc 1992;40:922-935.

4. Boustani M, Peterson B, Hanson L, Harris R, Lohr KN; U.S. Preventive Services Task Force. Screening for dementia in primary care: a summary of the evidence for the U.S. Preventive Services Task Force. Ann Intern Med 2003;138:927-937.

5. Park J, Kwon Y. Standardization of Korean Version of the Mini-Mental State Examination (MMSE-K) for use in the elderly. Part II: diagnostic validity. J Korean Neuropsychiatr Assoc 1989;28:508-513.

6. Lee JH, Lee KU, Lee DY, Kim KW, Jhoo JH, Kim JH, et al. Development of the Korean version of the Consortium to Establish a Registry for Alzheimer's Disease Assessment Packet (CERAD-K): clinical and neuropsychological assessment batteries. J Gerontol B Psychol Sci Soc Sci 2002;57:P47-P53.

7. Kang Y, Na DL, Hahn S. A validity study on the Korean mini-mental state examination (K-MMSE) in dementia patients. J Korean Neurol Assoc 1997; 15:300-308.

8. Lee DY, Lee KU, Lee JH, Kim KW, Jhoo JH, Youn JC, et al. A normative study of the Mini-Mental State Examination in the Korean elderly. J Korean Neuropsychiatr Assoc 2002;41:508-525.

9. Han C, Jo SA, Jo I, Kim E, Park MH, Kang Y. An adaptation of the Korean mini-mental state examination (K-MMSE) in elderly Koreans: demographic influence and population-based norms (the AGE study). Arch Gerontol Geriatr 2008;47:302-310.

10. O'Connor DW, Pollitt PA, Hyde JB, Fellows JL, Miller ND, Brook CP, et al. The reliability and validity of the Mini-Mental State in a British community survey. J Psychiatr Res 1989;23:87-96.

11. Anthony JC, LeResche L, Niaz U, von Korff MR, Folstein MF. Limits of the 'Mini-Mental State' as a screening test for dementia and delirium among hospital patients. Psychol Med 1982;12:397-408.

12. Jhoo JH, Kim KW, Lee DY, Youn JC, Lee TJ, Choo IH, et al. Comparison of the performance in two different Korean Versions of MiniMental State Examination: MMSE-KC and K-MMSE. J Korean Neuropsychiatr Assoc 2005;44:98-104.

13. Feher EP, Mahurin RK, Doody RS, Cooke N, Sims J, Pirozzolo FJ. Establishing the limits of the Mini-Mental State. Examination of 'subtests'. Arch Neurol 1992;49:87-92.

14. Galasko D, Klauber MR, Hofstetter CR, Salmon DP, Lasker B, Thal LJ. The Mini-Mental State Examination in the early diagnosis of Alzheimer's disease. Arch Neurol 1990;47:49-52.

15. Hodges JR, Salmon DP, Butters N. Differential impairment of semantic and episodic memory in Alzheimer's and Huntington's diseases: a controlled prospective study. J Neurol Neurosurg Psychiatry 1990;53: 1089-1095.

16. Imai Y, Hasegawa K. The Revised Hasegawa's Dementia Scale (HDS$\mathrm{R}$ )-evaluation of it's usefulness as a screening test for dementia. J Hong Kpng Coll Psychiatr 1994;4:20-24.

17. Kim KW, Lee DY, Jhoo JH, Youn JC, Suh YJ, Jun YH, et al. Diagnostic accuracy of mini-mental status examination and revised hasegawa dementia scale for Alzheimer's disease. Dement Geriatr Cogn Disord 2005;19:324-330.

18. O'Connor DW, Pollitt PA, Treasure FP, Brook CP, Reiss BB. The influence of education, social class and sex on Mini-Mental State scores. Psychol Med 1989;19:771-776.

19. Crum RM, Anthony JC, Bassett SS, Folstein MF. Population-based norms for the Mini-Mental State Examination by age and educational level. JAMA 1993;269:2386-2391.

20. Woo JI, Lee JH, Hong JP. Effect of age, sex and education on the scores of MMSE-K among the rural elderly residents. J Korean Neuropsychiatr Assoc 1996;35:122-132.

21. Park J, Lee YH. Effects of gender, age, and education on the performances of the Korean version of the Mini-Mental State Examination in an elderly rural population. J Korean Neuropsychiatr Assoc 1999;38:173180.

22. Park J, Lim S, Lim J, Kim K, Han M, Yoon I, et al. An overview of the Korean Longitudinal Study on Health and Aging. Psychiatry Investig 2007;4:84-95

23. Kang Y, Na DL. Neuropsychological Screening Battery Incheon: Human Brain Research \& Conculting Co; 2003.

24. American Psychiatric Association. Diagnostic and Statistical Manual of Mental disorders (4th ed). Washington, DC: American Psychiatric Association; 1994.

25. Kim HS. Hyeondae gugeo sayong bindo 2. Seoul: The National Institute of the Korean Language; 2005.

26. Korean Statistical Information Service. Available at: http://www.kosis.kr/. Accessed; 2009.

27. Morris JC. The Clinical Dementia Rating (CDR): current version and scoring rules. Neurology 1993;43:2412-2414.

28. Hanley JA, McNeil BJ. A method of comparing the areas under receiver operating characteristic curves derived from the same cases. Radiology 1983;148:839-843.

29. Masur DM, Sliwinski M, Lipton RB, Blau AD, Crystal HA. Neuropsychological prediction of dementia and the absence of dementia in healthy elderly persons. Neurology 1994;44:1427-1432.

30. Linn RT, Wolf PA, Bachman DL, Knoefel JE, Cobb JL, Belanger AJ, et al. The 'preclinical phase' of probable Alzheimer's disease. A 13-year prospective study of the Framingham cohort. Arch Neurol 1995;52:485490.

31. Hughes CP, Berg L, Danziger WL, Coben LA, Martin RL. A new clinical scale for the staging of dementia. Br J Psychiatry 1982;140:566-572. 